\title{
MARKETING THE SURVEYING AND GEOSPATIAL PROFESSIONS
}

\author{
John C Trinder \\ School of Civil and Environmental Engineering, UNSW SYDNEY NSW 2052, Australia (j.trinder@unsw.edu.au)
}

Commission VI - WG VI-3

KEYWORDS: Surveying, Spatial Information, Education, International Cooperation, Marketing

\begin{abstract}
:
Many universities around the world are experiencing a decline in the number of students entering programs in surveying and geospatial engineering, including some institutions with prestigious pasts. For Australia, this raises the question of whether there will be adequate graduates in the future to replace the current cohort of surveying and geospatial professionals when they retire. It is not clear why it has not been possible to attract more school leavers into the surveying and geospatial programs, but it may be because the community at large is unaware of the many career opportunities. Several surveys have been carried out in Australia to determine the status of graduates entering the profession and the impact that shortages of graduates in the surveying and geospatial professions in the future. These shortages could seriously limit the development of infrastructure and housing if they are not overcome. Another issue is whether the demand for graduates is changing due to developments in technology that allow surveying and mapping to be undertaken more quickly and efficiently than in the past. Marketing of education programs into schools and the general population is essential. A solution maybe for a concerted global effort to encourage more school leavers to enrol in surveying and geospatial engineering programs and hence improve the viability of the profession for the future. The paper will review the impacts of shortages in graduates entering the profession and approaches to improve the marketing of the surveying and geospatial professions.
\end{abstract}

\section{INTRODUCTION}

The continued decline in enrolments in Universities and Vocation Education Training (VET) colleges in Australia commenced about 20 years ago. This phenomenon is not limited to Australia since it has occurred in many other developed countries. Australia is a large country of about 8 million $\mathrm{km}^{2}$ with a relatively small population which occupies mainly the coastline along the south and east because the centre is arid and receives limited rainfall. There are 38 universities located in the capital cities and regional centres. Professional education in surveying and geospatial engineering is undertaken in universities in most states with limited staff numbers. In 2007 it was estimated (Trinder 2007) that enrolment numbers in surveying at that time should be doubled until the shortage of graduates is overcome, but this has not happened.

The viability of education programs in surveying and geospatial engineering at academic institutions in Australia has been raised by others over the past decade or so, with little improvements in the status of enrolments. For example, the course in the state of South Australia, where the capital city is Adelaide, has been closed down and the profession is currently partly funding a postgraduate course to continue the education of qualified surveying graduates in South Australia. In several other states programs are being taught by as little as 2 or 3 academic staff with little chance of recruiting additional staff. As a consequence of low enrolments at the University of NSW, the School of Surveying and Geospatial Engineering was disestablished and merged with the School of Civil and Environmental Engineering in 2013, thus losing its identity as a separate school. The subject of low enrolments in surveying and geospatial engineering has been considered by organizations such as ISPRS and FIG in the past and it seems to be a characteristic of education institutions in the developed countries. The cause of this decline in enrolments in academic institutions is unclear, but direct and indirect impacts include:
- Reduced graduates entering the professions leading to inadequate professionals to undertake essential services;

- Reductions in funding for education institutions leading to department closures;

- Losses of qualified teaching staff often resulting in the need to import staff from other countries

- Lack of advanced level programs to upgrade the qualifications of first degree graduates and professionals who wish to gain knowledge of the latest developments

- Lack of postgraduate students to undertake funded research projects

- Loss of influence and even identity of the profession

These impacts are serious and will be discussed in more detail below.

\section{IMPACTS OF LOW ENROLMENTS IN EDUCATION INSTITUTIONS}

\subsection{Insufficient Graduates Entering the Profession}

Even though the demand for graduates may change in future, due to improvements in technologies, a recent study by BIS Shrapnel on the number of surveying and geospatial graduates entering the profession in Australia painted a bleak future for the future supply, with the impact that AUD30.4 billion in construction work and 14,570 private housing commencements will be at risk from surveyor skills shortages. An additional study by ACIL Tasman (2013) (now named ACIL Allen Consulting) projected a shortage of about 1800 surveying and geospatial professionals within about 10 years. There will also be a less significant shortage of surveying and geospatial engineering technicians over the same period. The ultimate impact of the skills shortages is a lack of capacity in the community which will affect the economy of Australia. As well as infrastructure and housing works, large engineering and 
mining projects also require significant numbers of surveying and geospatial professionals. Overall there will be a significant impact on the economy of the country if these shortages are not addressed.

\subsection{Reduced Funding for Education Institutions}

The reductions in enrolments at academic institutions can lead to loss of funding, with a consequent loss of staff and hence quality of teaching, since part-time teachers would be required to fill the vacancies in the teaching programs. The ultimately consequence of loss of funding is closure of the department/school. Fewer academic staff will also result in reduced ground breaking research and developments as well as theoretical studies that are essential to support the local and international fields of surveying and geospatial engineering. Many new developments in technologies applied to surveying and geospatial fields have originated from research undertaken by staff and postgraduate students in universities.

\subsection{Loss of Qualified Teaching Staff}

The lack of students and loss of funding also mean that there are no or insufficient high quality graduates who would be trained through the postgraduate research programs to become academic staff. Therefore staff must be recruited from other countries; these staff are not usually familiar with in particular, the local legislation on land registration and may not be in a position to teach these subjects. Hence other solutions need to be found for teach these details.

\subsection{Lack of Advanced Education Programs}

The content of generalist first degree programs in surveying and geospatial engineering can never include material in sufficient depth to enable graduates to specialise in advanced levels of the fields, particularly covering new developments in methods and technologies, for example, advanced levels of remote sensing and photogrammetry. Therefore, as is the case with most engineering programs, advanced programs should be made available to graduates to update their qualifications or specialise in more depth in a particular area. As well, after working for a decade or so professionals often wish to upgrade their skills. There is a need for such advanced programs, but due to lack of students and staff, such programs cannot be offered by academic institutions in Australia. An alternative, but not yet attempted, could be nation-wide web based courses.

\subsection{Lack of Postgraduate Students}

Postgraduate students are often the major contributors to research for externally funded projects. Without adequate postgraduate students, these research projects cannot be developed, thus further reducing research output in the surveying and geospatial areas.

\subsection{Loss of Influence and Identity of the Profession}

Because of the gradual loss of high quality professionals and the possible future assumption of their roles by less qualified individuals who fill the gap left by the declining numbers of professionals, the profession would lose influence in the community and in government. Surveyors and geospatial professionals play many important roles in the community including: ensuring high quality positioning systems around the nation; maintenance of standards of measurement of land, the integrity of the land titling and registration system; and provision of the fundamental digital spatial information on which all development and environmental management is based. Unless the profession has sufficient size, its influence in these areas will be diminished and hence the maintenance of high standards of spatial information in the community may be lost.

\section{MARKETING THE PROFESSIONS}

The above impacts will be serious for the community if not addressed. Improved marketing of the professions is essential to increase the number of graduates entering the profession. One important question that should be analysed is why school leavers are not interested in the surveying and geospatial professions as career options, or alternatively what would encourage school leavers to join the surveying and geospatial professions in future?

A report in Australia by the company Prism (2012) on needs for development of Destination Spatial Queensland in the state of Queensland (see below for further information on this web site), discussed a number of actions that could be taken by organizations wishing to publicise the surveying and geospatial professions. These include: statements about the availability of jobs and career opportunities; details of articulation of career pathways; definition of enrolment targets; obtaining accurate industry and career information; support for web based information on careers; identification of areas in which school curriculums could support the development of spatial skills and knowledge; working with teachers to help them develop the skills they need to teach the curriculum; and developing sustainable relationships with teachers, schools and students.

The report included estimates of the substantial sums that could be required to commercially market surveying and geospatial courses in the state of Queensland in Australia. The states of Victoria and South Australia have also invested significant sums to support the marketing of surveying and geospatial careers. It is therefore important to make the careers advisors in schools aware of the professions in order to inform the population of school students of the benefits of entering the surveying and geospatial profession. Some examples of marketing that could be undertaken in Australia are described in more details below.

\subsection{Web Site Development}

There is a clear need to provide comprehensive information about career opportunities on purpose built web sites. Therefore emphasis should be given to the development and maintenance of attractive and informative web sites featuring such information as: links providing entry requirements to academic institutions; descriptions of career opportunities and options; examples of professionals in their working environment; video clips of professionals describing their activities at work; and articulation options to improve career opportunities. There are many exciting new developments in the surveying and geospatial industries, including (Lawler 2013):

- With almost unlimited computing power on the cloud and big data enabling real-time analytics, we are approaching the capability to capture digitally, visualize and model our entire built environment.

- There is a convergence of GIS, BIM and visualization and animation.

- With increased scale of computing the trend is to move to higher levels of information organization, including 
augmented reality which will become personalized and contextualized, wearable computing devices, sensors, smart phones, and tablets.

- Maps will be based on full 3D with rendering from multiple sensors. Spatial resolution of the data will need to be very high with high update rates.

- Crowd sourcing, machine learning and big data, are all developments in the digital world. Computing will be extended to billions of fully connected nodes, enabling an end-to-end approach - from sensor, acquisition of data to user experience.

- Geospatial information is important because life is getting more complex. It is said to be the great enabler.

- The multi station instrumentation enables faster and more accurate measurements.

- Digital aerial cameras are now used almost exclusively in most countries capturing imagery over thousands of $\mathrm{km}^{2}$ per day; they can lead to the collection of 200 to 300 3D points $/ \mathrm{m}^{2}$.

- UAS are significantly changing the way data is collected.

- Aerial lidar systems are becoming faster and collecting more dense data, eg up to 100 points $/ \mathrm{m}^{2}$.

- Petabytes of satellite data in data cubes are now required to support government environmental programs.

These are exciting technological developments which require graduates with advanced levels of education.

In Australia there are two existing web sites which describe pathways to the surveying and geospatial professions, namely http://www.destinationspatial.org/ and http://www.alifewithoutlimits.com.au/. Attempts are made to keep both of these sites up-to-date with limited funds. A taste of the future developments in surveying and geospatial fields is required to be displayed on these web sites, based on expert input from professionals, teachers, practitioners and researchers with knowledge of current and future trends in the professions. It would certainly be of benefit to these web sites if there could be international cooperation in their development.

\subsection{Working with Secondary School Teachers and Placing Technologies in Schools}

An effective way to encourage students into surveying and geospatial programs is to work closely with geography, mathematics and science teachers to ensure aspects of these topics are included in school curricula. This contact can include presenting students in secondary and even primary schools with spatial problems. The task of providing appropriate spatial software to schools is no longer the problem it once was since tools are now available through Google Earth and other packages. Experience around the world has demonstrated the advantages of exposing students to spatial tools early in their learning experience.

\subsection{Mentoring and Internships}

Mentoring by working professionals can assist in exposing prospective students to typical working environments and tasks. This can be managed through professional bodies which arrange for volunteer professionals to link up with students and allow them to witness the working environment of the professional. Internships, while more expensive, are a more permanent way of exposing students to the work environment. Some international companies use internships very successfully.

\subsection{Social Media}

It is clear that social media such as on Facebook, Twitter and YouTube, should play a role in marketing the surveying and geospatial professions. It is unlikely that prospective students will regularly visit a website for updates, however if they 'like' a page on Facebook or follow a group on Twitter they should see updates appear in their newsfeeds. The benefits of a well thought out social media strategy will be greater than just having, for example, a "Twitter" strategy. All sources of information should be interconnected with each other and with the campaign's website. A comprehensive social media strategy results not only in a reduction in the time resource per social media type, but an increase in its effectiveness. For example, all status updates on social media should be synchronized so one update will update all. By linking social media sites to the website's home page, search engine rankings should be significantly improved, leading to more traffic. Tracking how many followers or 'likes' that the account has could be one possible measure of success. In a similar way, 'hits' on the various web pages could also be monitored to determine if there is an increase in activity during the campaign.

\subsection{Other forms of Advertising}

Advertising in traditional forms such as brochures and leaflets are always needed, but the details should be sourced from the details on the web sites. As well, attendance at 'careers markets' is necessary since these markets display a range of careers to high school students. While the number of enquiries at careers markets may be low, since the number of enrolments into academic institutions is of the order of 1 student from every 5 to 10 schools, it is still necessary have a presence..

\section{CONCLUSIONS}

The impacts of reduced enrolments in academic courses for the surveying and geospatial professions are likely to be serious from a number of points of view, but the most significant are the reductions in the number of professionals to undertake the essential work for infrastructure development, construction, and maintenance of the cadastre. There is a need to market surveying and geospatial careers to ensure that the services provided by these professions continue. International cooperation in developing web sites, videos, social media would be beneficial to all organizations responsible for this marketing task.

\section{REFERENCES}

ACIL Tasman 2013 Surveying and geospatial workforce modelling pp124

BIS Shrapnel 2013 Determining the Future Demand, Supply and Skills Gap for Surveying and Geospatial Professionals, Report to Consulting Surveyors National pp130.

Lawler S. 2013 '3D Mapping and Photogrammetry' Proceedings Photogrammetric Week, Stuttgart Germany, pp343-346.

Prism 2012 Report on 'Destination Spatial (Q1d) Communication and Engagement Strategy 2012/13 to 2014/15' Trinder J C 2007 Geomatics Education in Australia GIM magazine July 20077 pages. 